Serviço de Patologia e Clínicas Cirúrgica e Obstétrica Prof. Dr. R. Straunard

\title{
ESPOROTRICOSE EM MUAR (*)
}

\author{
S. N. Piratininga \\ Assistente \\ 2 estampas ( 3 figuras)
}

Em Maio de 1941 foi apresentado, ao Ambulatório da Clínica, um muar, com 10 anos de idade, portador de numerosas lesões cutâneas, disseminadas, e que datavam de alguns meses, mostrando-se rebeldes aos vários tratamentos indicados por leigos.

Verificam-se, ao exame do animal, lesões muitissimo interessantes, de tipo incomum, por nós observadas pela primeira vez. $\mathrm{O}$ aspecto é multiforme : destruição do tecido cutâneo em determinados pontos; em outros, nódulos endurecidos ou de consistência mole por conteúdo liquido, purulento, supurados ou não, ao lado de úlceras e crostas. Os pêlos, conglutinados pelo pus, formam tufos irregulares ao redor das lesões. Pela queda ou retirada das crostas, em alguns pontos, o tecido subjacente é de tipo cicatricial, esbranquiçado, retraindo a pele normal proxima. E' facil reconhecer, nessas lesões, a evolução característica das gomas.

Predominam as alterações no lado esquerdo do muar; localisam-se na porção anterior do peito, porção inferior esquerda do torax, face externa do ante-braço esquerdo, ventre, prepúcio e face interna das coxas (Figuras 1 e 2). Em determinadas regiões elas se dispõem ordenadamente, em trajeto linear, como seguindo os vasos linfáticos.

Pela anamnese soubemos que a dermatose se iniciou no lado esquerdo do torax, porção inferior (Figura 3), revelando-se pelo aparecimento de vários nódulos que supuraram, determinando ulcerações, com perda maior ou menor do tecido cutâneo local. A partir dêsse ponto desenvolveram-se as lesões, gradativamente, atingindo as outras regiões mencionadas.

Alguns gânglios se apresentam tumefatos, pouco sensiveis, como os cervicais profundos, do lado esquerdo, e os inguinais, superficiais e profundos. Os cervicais superficiais (pré-escapular) do lado esquerdo e os popliteos supuram. A adenite dos cervicais profundos é bem aparente (Figura $1-\mathrm{A}$ ).

(*) Nota prévia à Sociedade Paulista de Medicina Veterinária, em 9-9-1941. 
Di a g nó s ti co. - Ao simples exame clínico do animal, considerado o tipo das lesões - nódulos e gomas em estados diferentes de evolução - e não raro, a disposição de muitos elementos no trajeto de vasos linfáticos, já se presumiu tratar-se de Esporotricose, diagnóstico, dias depois confirmado pelo exame histopatológico de biópsia de uma das lesões mais típicas (do prepúcio) e pelo desenvolvimento cultural de pus semeado em meios de prova maltosado e glicosado de Sabouraud.

Nos cortes, as lesões tecidulares, sem que fossem patognomônicas, indicavam a natureza micótica provavel do processo : zona central de reação supurativa com grande quantidade de polinucleares, zona de células epitelioides com alguns gigantocitos de permeio e, por fim, zona externa ou marginal com acentuada reação linfo-conjuntiva e lesões de vascularite e de perivascularite. Mas, foram as culturas obtidas que tornaram o diagnóstico indubitavel. De desenvolvimento precoce, em 6 e 8 dias mostraram-se sob a forma de pequenas colonias claras, de começo, logo depois de côr crême, em seguida café com leite e, por fim, fuliginosas e negras; eram salientes, de superficie irregular, montanhosas, com circunvoluções e pigmentando-se primeiro a periferia, estendendo-se depois o pigmento à colonia inteira, tudo diferenciando-as das do $S p$. Gougeroti, cuja pigmentação é negra já de início e classificando-se nas do Sp. Beurmanni.

A solução iodo-iodurada, em aplicação local, e o iodeto de potássio, por via oral, constituiram os meios de tratamento, observando-se melhoras acentuadas, mas de modo muito lento.

Moléstia intercorrente determina a morte do animal em pleno período de tratamento, em condições que impossibilitaram uma necroscopia, despojando-nos, infelizmente, de dados de valor para o estudo de tão interessante observação.

Casos vários de Esporotricose já foram observados, em diferentes lugares, em animais. Assim, segundo Hutyra, Marek e ManNINGER, em cavalos e muares, em Madagascar (CARougeaU), nos Estados Unidos (C. e J. Page, Frothingham, K. F. Meyer), no Canadá (WATSON), na India (Holmes); em um dromedário, na Síria (Challlot); em cães, na França (Gougerot e Caraven, Collet). 
No Brasil, excluindo as observações em ratos, por LuTz e SPLENDORE, encontramos, em animais domésticos, somente dois casos relatados : em muar, no Rio de Janeiro, por A. E. DE AREA LEÃo, J. Olegario da Silva e Manoel Proença; em jumento, em São Paulo, por Alexandre Mello.

Constitue esta observação, portanto, o terceiro caso de Esporotricose, em animal doméstico, verificado no Brasil, e o segundo em São Paulo. Julgamos, no entanto, que não deve ser rara a moléstia em nossos animais, sobretudo nos muares, nos cavalos e bovinos. A indagação cultural sistemática, em casos de lesões cutâneas com o aspecto clínico dessas por nós observadas, diria da sua frequência.

A confirmação do diagnóstico clínico foi feita pelo Prof. A. Martins de Castro. Pelo valor indiscutivel da sua contribuição, o nosso sincero agradecimento.

\section{SUMMARY}

The author describes a case of Sporotrichosis in mule, by the Sp. Beurmanni. The animal presented numerous skin lesions, disseminated, predominant on the left side, situated on the anterior portion of the breast, inferior left portion of the thorax, external surface of the left forearm, belly, prepuce and internal surface of the thighs. The aspect of the lesions was multiform: loss of cutaneous tissue at some points; at others, hard nodules, or of soft consistency due to purulent containt, supurated or not, beside ulcers and crusts. In some regions the lesions were orderly disposed, in linear traject, as if following the lymphatic vessels. The deep cervical glands on the left side, and the superficial or deep inguinal ones, appeared tumid. The superficial cervicals glands (prescapular) on the left side and the popliteal glands supurated. Sowing pus in Sabouraud's maltose and glucose test medium, colonies were developed with the typical characteristics that permitted the identification of Sp. Beurmanni.

This case constitutes the third observation of Sporotrichosis in domestic animals in Brazil, and the second in Säo Paulo.

\section{BIBLIOGRAFIA}

Area leão, A. E. de - Silla, J. Olegario da - Proença, M. - 1935 - Sur un cas de sporotrichose a "Sporotrichum Beurmanni" (Observé pour la première fois chez un mulet). Bol. Vet. Exército, Rio de Janeiro 2. (3) : 45-9. 
Hutyra, F. - MareK, J. - Manninger, R. - 1938 - Special pathology and therapeutics of the diseases of domestic animals. 4th. ed. London, Baillière, Tindall \& Cox, 1: 715 .

LUTZ, A. - SPLEndore, A. - 1907 - Sobre uma mycose observada em homens e ratos. (Contribuição para o conhecimento das assim chamadas sporotrichoses). Rev. med. S. Paulo, 10 (21): 433-50.

Mello, A. - 1935 - Um caso de esporotrichose verrucoide por "Sporotrichum Beurmanni". Rev. Ind. Animal, S. Paulo, 2 (3): 305-14. 


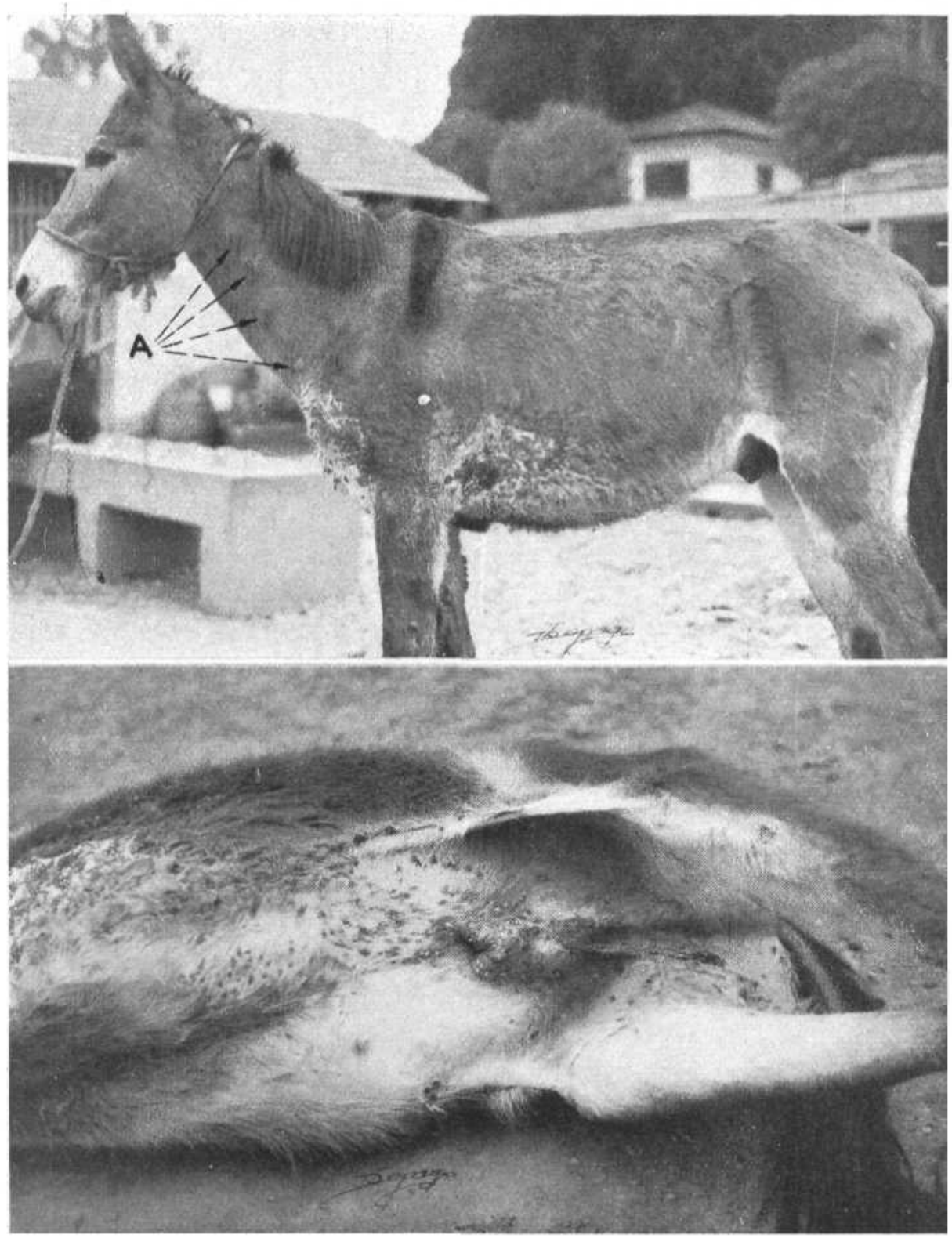




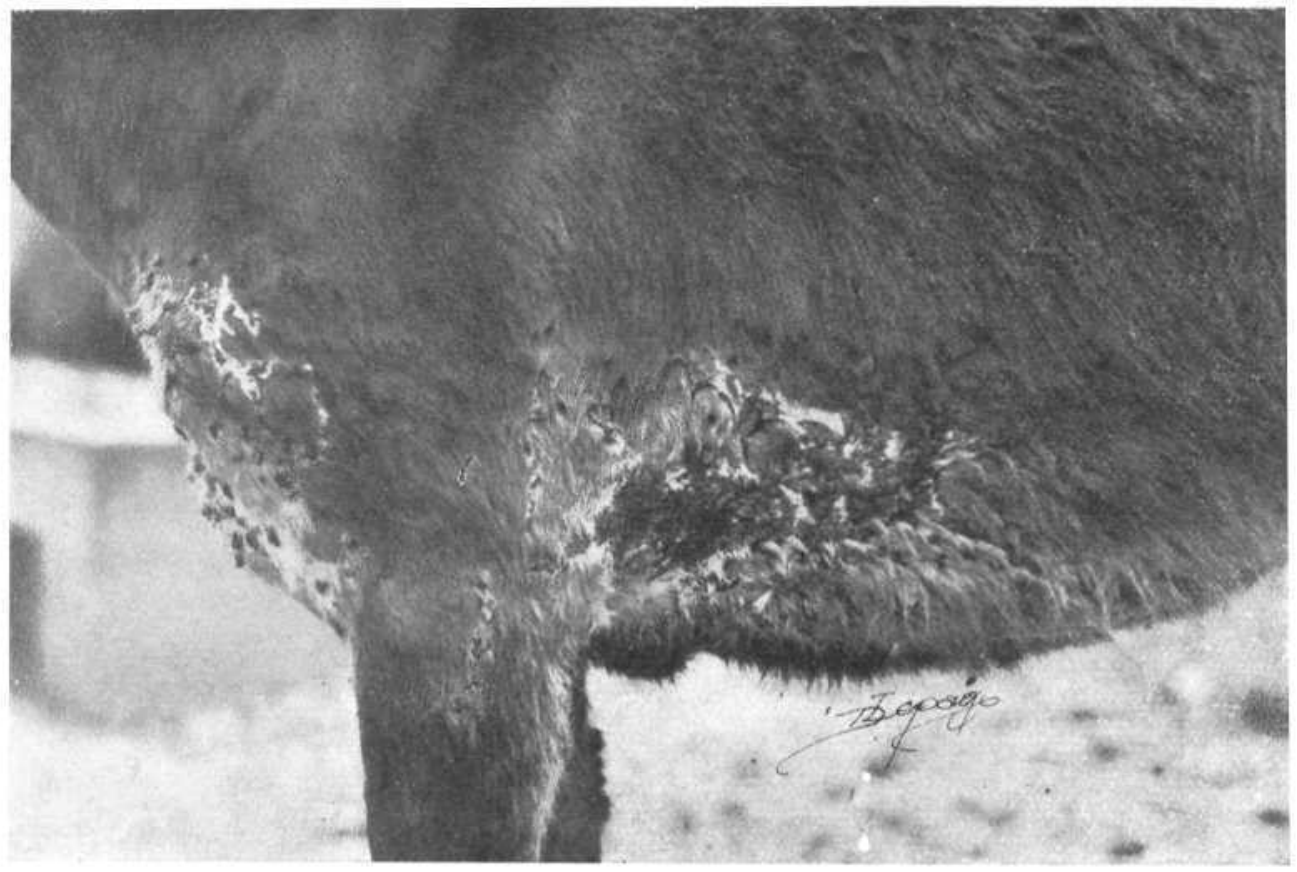

